\title{
Oral Health Status of Children With High Risk of Sleep- Disordered Breathing
}

\author{
Basma Tamasas, BDS, MS, PhD'; Garett Godfrey, DDS, MSD²; Travis Nelson, DDS, MSD, MPH²; Maida Chen, MD
}

${ }^{1}$ Department of Oral Health Sciences, University of Washington, Seattle, Washington; ${ }^{2}$ Department of Pediatric Dentistry, School of Dentistry, University of Washington, Seattle, Washington; ${ }^{3}$ Department of Pediatrics, Division of Pulmonary and Sleep Medicine, University of Washington School of Medicine, Seattle, Washington; ${ }^{4}$ Pediatric Sleep Disorders Center, Seattle Children's Hospital, Seattle, Washington

\begin{abstract}
STUdy ОвJестіves: To evaluate caries, gingival and periodontal status, and oral health-related quality of life (OHRQoL) in children with high risk of sleep-disordered breathing (SDB) in comparison to those with low risk of SDB.

Methods: This cross-sectional study recruited consecutive children between the ages of 8 to 17 years from a university-based pediatric dental clinic. Caregivers completed the Pediatric Sleep Questionnaire (PSQ) to stratify risk of SDB. Children and their caregivers completed the Child Oral Health Impact Profile (COHIP) to measure OHRQoL. A dental examination blinded to the results of the PSQ and COHIP was conducted. Group characteristics were compared between those with high risk (SDB+) and low risk for SDB (SDB-).

Results: One hundred twenty-three children were enrolled (11.5 \pm 2.7 years, female $=48 \%)$. Forty-nine percent were classified as $\mathrm{SDB}+$. COHIP scores were higher among the SDB+ group ( 24.5 versus $11.6, P<.001$ as reported by caregivers, and 25.9 versus 10.3 , $P<.001$ as reported by children). The incidence of dental caries present on examination was higher $(60 \%$ versus $20 \%, P<.001)$ in the $\mathrm{SDB}+$ group. In addition, the indices of periodontal diseases were higher among the SDB+ group when compared to the SDB- group (periodontal pocket depth was $2.0 \pm 1.0$ versus $0.0 \pm 0.7, P<.0001$, and bleeding on probing was $90 \%$ versus $20 \%, P<.001$ ).

Conclusions: This study suggests that caregiver reports of SDB symptoms in those seeking pediatric dental care are common. In addition, children in the SDB+ group had poorer OHRQoL, with increased incidence of caries lesion and periodontal disorders when compared to the SDB- group.

KEY WORDS: dental caries, obstructive sleep apnea, oral health-related quality of life, periodontal diseases, sleep-disordered breathing Citation: Tamasa B, Godfrey G, Nelson T, Chen M. Oral health status of children with high risk of sleep-disordered breathing. Journal of Dental Sleep Medicine. 2018;5(2):31-38.
\end{abstract}

\section{INTRODUCTION}

Sleep-disordered breathing (SDB) comprises a group of disorders characterized by abnormal respiratory patterns and ventilation. The prevalence of SDB in children is approximately $2 \%$ to $5 \% .{ }^{1,2} \mathrm{SDB}$ ranges from primary snoring to obstructive sleep apnea (OSA). OSA is characterized by a partial or complete collapse of the upper airway during sleep, resulting in partial or complete cessations of breathing (hypopnea, apnea), leading to the disruption of normal sleep architecture and oxygen desaturation. ${ }^{3,4}$ OSA has a serious effect on the growth and development of a child; if untreated, OSA may lead to significant morbidity including vascular and metabolic disorders and neurocognitive dysfunction, ultimately leading to reduced quality of life and increased medical expenses. ${ }^{5,6}$

Oral diseases are major public health issues as a result of considerable function impairment, reduced quality of life, and the costly treatment. ${ }^{7}$ Cumulative evidence supports a link between systemic diseases or health complications and oral diseases. ${ }^{8}$ Contrary to the well-studied systemic complications, the risk of oral complications in children with SDB is not well recognized. In fact, only one study investigated the oral health of Saudi children (3 to 8 years) with snoring and clinically diagnosed OSA. A lower prevalence of dental caries, plaque deposition, and gingival inflammation compared to healthy controls was reported. However, the investigators only targeted younger children with mainly primary dentition, and did not look into risk factors associated with caries, such as socioeconomic status. ${ }^{9}$ Because failure to recognize oral health complications in children with SDB can increase the personal and economic burden for affected individuals, their caregivers, and community, further investigations of oral health issues are warranted in this pediatric population

Children with SDB have oral manifestations such as tonsillar hypertrophy, narrow dental arches, macroglossia, malocclusion, and mouth breathing. ${ }^{10,11}$ In spite of the extensive description of these manifestations as key findings for SDB diagnosis, there is little understanding of their consequences on the oral health of the affected population. Snoring and OSA accompanied by unhealthy open mouth breathing are known to cause dry mouth, which if untreated can have detrimental effects on oral health. ${ }^{12-14}$ Acar et al. found that longer duration of snoring leads to increased exposure time to a dry mouth, and therefore poor oral health in adults. ${ }^{15}$ Dry mouth can also occur during treatment of patients with OSA using continuous positive airway pressure devices. ${ }^{16}$ Tsuda et al. reported that $40 \%$ of adults on continuous positive airway pressure for OSA have poor oral health. ${ }^{17}$ Moreover, recent studies have shown that OSA can activate various inflammatory processes, which when coupled with a dry mouth, 
increase the risk and severity of periodontal disease in adult patients with OSA. ${ }^{18,19}$

The improvement of the dental health of all children is recognized as a global public health concern..$^{20}$ Thus, it is imperative to identify children at high risk for caries and implement early oral health preventive strategies to reduce the burden of dental care. To date, studies investigating the oral health status in adult patients with SDB are limited, and data for children are scarce. Therefore, the purpose of this study is to compare the oral health status of a group of children at risk of SDB with that of healthy children. Information gleaned from this study may prompt more rigorous attention to the oral health of the SDB population.

\section{METHODS}

\section{Study Design}

This cross-sectional study was conducted at a university-based pediatric dental clinic at the University of Washington between October 2016 and January 2017. We approached potential subjects at the time of their routine dental checkups. Inclusion criteria required that the subject was 8 to 17 years old at the time of enrollment, in good overall health, and did not have active orthodontic treatment within the past year. Children and their caregivers were also required to be fluent in English. The following exclusion criteria were applied: subjects with craniofacial diagnoses; systemic conditions (eg, arthritis); neurologic disease; or cognitive impairment compromising their ability to maintain good oral health. The study was approved by the University of Washington Institutional Review Board with written informed consent/assent obtained from each participant and/or their legal representative, as appropriate.

\section{Questionnaires}

After consenting/assenting to participate, caregivers were asked to complete the Pediatric Sleep Questionnaire (PSQ) to determine whether their child was at risk for SDB. ${ }^{21}$ This validated questionnaire consists of 22 items forming 3 distinct domains: snoring, daytime sleepiness, and related behavioral disturbances, an overall score of at least 8 indicates positive SDB symptoms. The PSQ was developed as a research tool only, and thus no clinical care recommendations are standardized for results of this questionnaire. Participants with abnormal PSQ scores or stated concerns were advised to bring their concerns to the primary care providers. The subjects' oral health-related quality of life (OHRQoL) was assessed based on the answers given by the children and their caregivers to the Child Oral Health Impact Profile (COHIP) questionnaire. ${ }^{22}$ This validated questionnaire consists of 35 items forming 5 conceptually distinct domains: oral health (oral symptoms such as teeth pain, or sensitivity and oral sores), functional well-being (the child's ability to perform specific everyday activities), social/ emotional well-being (peer interactions and mood states), school environment (assignments associated with the school environment), and self-image (positive feelings about self). The COHIP used Likert-type scales where "never" $=0$; "once or twice" $=1$; "sometimes" $=2$; "often" $=3$; and "very often" $=4$.
For some items, the scale was reversed to consistently make a higher score indicative of bad oral health. A subscore for each of the five COHIP domains and an overall total COHIP score were calculated. For the overall scores, higher scores reflect worsened OHRQoL. Patient demographics such as age, sex, and parental education were gathered as a part of the COHIP questionnaire completed by the caregivers.

\section{Dental Examination}

The clinical examinations were carried out by the same trained dentist (BT), who was blinded to results of the PSQ. The examinations were conducted using a dental mirror and a ball-ended periodontal probe. Intraexaminer reliability was measured and an intraclass coefficient threshold of 0.87 was reached. Oropharyngeal soft-tissue features and dental occlusion were recorded. Soft palate morphology was classified according to the Mallampati classification. ${ }^{23}$ Tonsil size was classified according to the Brodsky score. ${ }^{24}$ The recorded variables for dental occlusion included molar occlusion (I, II or III), overjet (in millimeters), overbite (percentage), and crowding. ${ }^{25}$ The diagnosis of dental caries was based on the detection of carious lesions at the cavitation stage, as recommended by the World Health Organization. ${ }^{25}$ Decayed, missing, and filled surfaces scores (DMFS for permanent teeth, dmfs for primary teeth) were used. ${ }^{25}$ The periodontal examination was performed for the Ramfjord index teeth (tooth number: 3, 9/F, 12/I, 19, 25/P, 28/S), separate recordings were made for the four smooth surfaces of these teeth, and an average tooth score was then recorded. ${ }^{26}$ Two periodontal indices were measured to assess periodontal status: (1) bleeding on probing, an indicator of the periodontal condition and disease progression recorded after stimulating the region where gingiva and teeth come into contact with each other by a periodontal probe; and (2) probing depth, defined as the distance between the gingival margin and the bottom end of the periodontal pocket, a probing depth greater than $2 \mathrm{~mm}$ is typically considered to be abnormal. ${ }^{27}$

\section{Statistical Analyses}

Data were summarized using frequency for qualitative variables and mean and standard deviation for quantitative variables. Subjects were initially stratified by risk of SDB, with those scoring at least 8 on the PSQ as high risk for SDB (SDB+) and those who scored below 8 as low risk for SDB (SDB-). Comparisons between the $\mathrm{SDB}+$ and $\mathrm{SDB}$ - groups were carried out by either chi-square tests or $t$ tests. Linear and logistic regression analyses were carried out to assess the effect of various variables on the different outcomes in the study. The level of significance was set at $P<.05$. All statistical analyses were carried out using the SPSS 22 statistical software package (SPSS, Inc., Chicago, Illinois, United States).

\section{RESULTS}

A total of 123 patients were enrolled. Mean age was $11.5 \pm 2.7$ years, and females constituted $48 \%$ of the sample. Thirteen percent of the participants had a body mass index for age over the 85th percentile-consistent with overweight/obesity. This likely reflects the general demographic of the area, but may 
Table 1-Characteristics of the study population.

\begin{tabular}{|c|c|c|c|c|c|}
\hline \multicolumn{2}{|c|}{ Sociodemographic Variables } & SDB- $(n=63)$ & $\mathrm{SDB}+(n=60)$ & Total $(n=123)$ & $P$ \\
\hline \multicolumn{2}{|l|}{ Age, years, mean \pm SD } & $11.5 \pm 2.8$ & $11.8 \pm 2.6$ & $11.5 \pm 2.7$ & .47 \\
\hline \multirow{6}{*}{ Race/ethnicity } & American Indian or Alaskan & $6(10)$ & $0(0)$ & $6(5)$ & \multirow{6}{*}{$.003^{*}$} \\
\hline & Asian & $9(15)$ & $6(10)$ & $15(12)$ & \\
\hline & Black or African American & $8(13)$ & $3(5)$ & $11(9)$ & \\
\hline & Hispanic or Latino & $3(5)$ & $15(25)$ & $18(15)$ & \\
\hline & White & $26(43)$ & $26(40)$ & $52(42)$ & \\
\hline & Other & $8(14)$ & $13(20)$ & $21(17)$ & \\
\hline \multirow{4}{*}{$\begin{array}{l}\text { Caregiver's educational } \\
\text { level }\end{array}$} & Less than high school & $2(3)$ & $5(9)$ & $7(6)$ & \multirow{4}{*}{.31} \\
\hline & High school diploma & $19(32)$ & $8(13)$ & $27(22)$ & \\
\hline & College degree & $31(52)$ & $31(52)$ & $62(50)$ & \\
\hline & Postgraduate degree & $8(14)$ & $19(27)$ & $27(22)$ & \\
\hline \multirow{3}{*}{ Family income } & $\leq \$ 39,999$ & $28(47)$ & $27(44)$ & $55(45)$ & \multirow{3}{*}{.745} \\
\hline & $\$ 40,000-\$ 59,999$ & $16(26)$ & $21(32)$ & $37(30)$ & \\
\hline & $\geq \$ 60,000$ & $16(26)$ & $15(25)$ & $31(6)$ & \\
\hline \multirow{4}{*}{ Dental insurance } & Private & $11(18)$ & $10(17)$ & $21(17)$ & \multirow{4}{*}{.74} \\
\hline & State sponsored & $40(67)$ & $44(68)$ & $84(68)$ & \\
\hline & Government programs & $8(13)$ & $9(15)$ & $17(14)$ & \\
\hline & None & $1(1)$ & $0(0)$ & $1(1)$ & \\
\hline \multirow{2}{*}{ Sex } & Male & $30(50)$ & $33(55)$ & $63(51)$ & \multirow{2}{*}{.40} \\
\hline & Female & $30(50)$ & $30(45)$ & $60(49)$ & \\
\hline \multirow{3}{*}{$\begin{array}{l}\text { Weight category based on } \\
\text { BMI }\end{array}$} & Normal & $51(85)$ & $57(91)$ & $108(88)$ & \multirow{3}{*}{.41} \\
\hline & Overweight & $3(5)$ & $2(2)$ & $5(4)$ & \\
\hline & Obese & $6(10)$ & $4(7)$ & $10(8)$ & \\
\hline \multirow{2}{*}{ Smoking in the household } & Yes & $7(12)$ & $5(8)$ & $12(10)$ & \multirow{2}{*}{.34} \\
\hline & No & $53(88)$ & $58(92)$ & $111(90)$ & \\
\hline \multirow{2}{*}{ Health problems } & Yes & $12(20)$ & $8(13)$ & $20(16)$ & \multirow{2}{*}{.82} \\
\hline & No & $48(80)$ & $55(87)$ & $103(84)$ & \\
\hline \multirow{2}{*}{ Snoring } & Yes & $54(90)$ & $2(2)$ & $56(46)$ & \multirow{2}{*}{$<.001^{*}$} \\
\hline & No & $6(10)$ & $61(98)$ & $67(54)$ & \\
\hline \multirow{2}{*}{ Sleepiness } & Yes & $56(93)$ & $6(10)$ & $62(51)$ & \multirow{2}{*}{$<.001^{*}$} \\
\hline & No & $4(7)$ & $57(90)$ & $61(49)$ & \\
\hline \multirow{2}{*}{ Behavioral symptoms } & Yes & $60(100)$ & $33(52)$ & $93(76)$ & \multirow{2}{*}{$<.001^{*}$} \\
\hline & No & $0(0)$ & $30(48)$ & $30(24)$ & \\
\hline
\end{tabular}

Values are presented as $\mathrm{n}(\%)$ unless otherwise indicated. ${ }^{*}=$ the level of significance was set at $P<.05$. BMl $=$ body mass index, $\mathrm{SD}=$ standard deviation, SDB = sleep-disordered breathing.

also reflect a recruitment bias in that those with perceived sleep concerns would more likely agree to participate in the study. Only $17 \%$ of children had health problems, with most of those children reporting a history of asthma (55\%) or attentiondeficit hyperactivity disorder (35\%).

Approximately half of the children were categorized into the SDB+ group based on PSQ score. According to caregiver responses, the $\mathrm{SDB}+$ group experienced significantly more behavioral symptoms, snoring, and daytime symptoms than the children in the comparison group (Table 1). All children with SDB (100\%) suffered from behavioral symptoms, 90\% were snorers, and the most frequently reported symptom was waking up with dry mouth (100\%). The frequencies of demographic and health-related variables assessed by SDB status are presented in Table $\mathbf{1}$.

A comparison of the mean COHIP scores of the study and the comparison groups revealed a statistically significant difference between four of the five subscales as well as the average total score, with the SDB+ group having higher mean scores than the control group (Table 2), consistent with 
Table 2-Comparison of overall and subscale COHIP scores for the SDB+ versus SDB- groups.

\begin{tabular}{|l|l|c|c|c|}
\hline & COHIP Item & SDB- $(\mathbf{n}=\mathbf{6 3})$ & SDB+ $(\mathbf{n}=\mathbf{6 0})$ & $\boldsymbol{P}$ \\
\hline & Overall COHIP & $10.3 \pm 9.4$ & $25.9 \pm 16$ & $<.001^{*}$ \\
\cline { 2 - 5 } & Oral health & $6.2 \pm 4.6$ & $13.5 \pm 6.3$ & $<.001^{*}$ \\
\cline { 2 - 5 } & Functional well-being & $0.6 \pm 1.8$ & $3.3 \pm 4.0$ & $<.001^{*}$ \\
\cline { 2 - 5 } & Social well-being & $1.4 \pm 2.9$ & $2.9 \pm 4.0$ & $.019^{*}$ \\
\cline { 2 - 5 } & School environment & $0.4 \pm 1.4$ & $0.9 \pm 1.6$ & .08 \\
\cline { 2 - 5 } & Self-image & $1.7 \pm 2.5$ & $5.3 \pm 5.0$ & $<.001^{*}$ \\
\hline \multirow{5}{*}{ COHIP/Caregiver } & Overall COHIP & $11.6 \pm 9.2$ & $24.5 \pm 12$ & $<.001^{*}$ \\
\cline { 2 - 5 } & Oral health & $8.1 \pm 5.7$ & $15.5 \pm 5.4$ & $<.001^{*}$ \\
\cline { 2 - 5 } & Functional well-being & $1.0 \pm 1.9$ & $2.8 \pm 3.0$ & $<.001^{*}$ \\
\cline { 2 - 5 } & Social well-being & $0.7 \pm 1.9$ & $2.0 \pm 4.0$ & $.02^{*}$ \\
\cline { 2 - 5 } & School environment & $0.4 \pm 0.8$ & $1.1 \pm 1.6$ & .11 \\
\cline { 2 - 5 } & Self-image & $1.4 \pm 2.5$ & $3.1 \pm 3.0$ & $<.001^{*}$ \\
\hline
\end{tabular}

Values are presented as mean \pm standard deviation. ${ }^{*}=$ the level of significance was set at $P<.05 . \mathrm{COHIP}=\mathrm{Child}$ Oral Health Impact Profile, $\mathrm{SDB}=$ sleep-disordered breathing

worse OHRQoL. No statistically significant differences were found between caregivers' and children's responses for overall COHIP, or for any of the subscales. In the logistic regression analysis, $\operatorname{dmfs}(\beta=.252, P=.001)$, DMFS $(\beta=.215, P=.01)$, weight $(\beta=.214, P=.01)$ and Brodsky score $(\beta=.234, P=.001)$ were significantly and positively associated with the COHIP score.

The result of the dental examination revealed that children with SDB were more likely to have overbite greater than $50 \%$ (22\% versus $11 \%, P=.05$ ), anterior crowding (68\% versus $23 \%$, $P<.001)$, Mallampati scores of II or higher (65\% versus $23 \%$, $P<.001$ ), and Brodsky scores of II or higher (66\% versus $31 \%$, $P<.001)$. There were no statistically significant differences in the prevalence of other oropharyngeal or orthodontic findings between SDB+ and SDB- groups. The prevalence of dental malocclusions and other oropharyngeal characteristics are presented in Table 3.

The overall caries prevalence was $60 \%$ in the SDB+ group and $20 \%$ for the SDB- group, $P<.01$. The mean of decayed, missing, filled primary surfaces ( $\mathrm{dmfs}$ ) was significantly higher among the $\mathrm{SDB}+$ group $(10.3 \pm 11.6$ versus $3.3 \pm 5.1, P<.001)$. Similarly, the mean of decayed, missing, filled permanent surfaces (DMFS) was significantly higher among the SDB+ group $(15.7 \pm 15.7$ versus $3.7 \pm 6.2, P<.001)$ (Figure 1$)$. The mean of periodontal pocket of sextants was significantly higher among the SDB+ group compared to the SDB- group $(2.0 \pm 1.0$ versus $0.0 \pm 0.7, P<.0001)$. Likewise, the percentage of sextants exhibiting bleeding upon probing was significantly greater among children with SDB $(90 \%$ versus $20 \%, P<.0001)$ (Figure 2). The results of the regression analysis showed that Brodsky scores were positively and significantly associated with each of the measured outcomes (ie, dmfs scores, $P=.005$; DMFS scores, $P=.05$; pocket depth, $P=.02$; and bleeding on probing, $P=.05$ ), whereas having dental insurance was negatively and significantly associated with pocket depth $(P=.01)$ and bleeding on probing $(P=.005)$.

\section{DISCUSSION}

In this community-based study we recorded a higher than previously estimated prevalence of SDB and parent-reported SDB symptoms in children. This study has also provided important baseline information on oral health status and the OHRQoL of children with SDB. SDB in children is associated with significant morbidities affecting the central nervous, cardiovascular, and metabolic systems, and growth. ${ }^{5,6}$ The findings of this study suggest that children with SDB experience poorer oral health than their peers. This information should prompt further investigation of oral health in the SDB population. It suggests that increased surveillance and treatment of SDB might improve oral health disparities in children.

Our study showed for the first time that SDB is associated with worse OHRQoL of children. We found that children with SDB have higher COHIP scores than control children for overall COHIP score, and for the oral health, functional wellbeing, and social-emotional well-being subscales. Intriguingly, based on the regression analyses, dental caries and adenotonsillar hypertrophy were significantly associated with higher COHIP score (ie, poor OHRQoL) in children with SDB. Our findings on the association of caries with OHRQoL are similar to those reported in previous studies. ${ }^{28,29}$ This may be explained by the fact that oral conditions such as dental caries can cause pain, discomfort, dysfunction, malnutrition, and inability to concentrate. ${ }^{29,30}$ The literature suggests a significant negative effect of adenotonsillar size on OSA symptoms, quality of life, and general well-being in children ${ }^{31,32}$; however, this is the first study to report the association between adenotonsillar size and the OHRQoL. Here we also reported a positive association between increasing body mass index and poor OHRQoL. Interestingly, despite the growing and significant literature on the effect of obesity on oral health, ${ }^{33}$ there is scarce literature on the effect of obesity on OHRQoL in the adult population ${ }^{34}$ and none in children. 
Table 3-Oropharyngeal and orthodontic morphology.

\begin{tabular}{|c|c|c|c|c|}
\hline \multicolumn{2}{|c|}{ Oropharyngeal and Orthodontic Morphology } & \multirow{2}{*}{$\begin{array}{c}\text { SDB- } \\
48(77)\end{array}$} & \multirow{2}{*}{$\begin{array}{c}\text { SDB+ } \\
22(35)\end{array}$} & $\boldsymbol{P}$ \\
\hline \multirow{4}{*}{ Mallampati } & I & & & \multirow{4}{*}{$<.001^{*}$} \\
\hline & II & $13(21)$ & $34(57)$ & \\
\hline & III & $2(2)$ & $4(8)$ & \\
\hline & IV & $0(0)$ & $0(0)$ & \\
\hline \multirow{4}{*}{ Brodsky } & 0 & $1(1)$ & $6(10)$ & \multirow{4}{*}{$<.001^{*}$} \\
\hline & I & $43(69)$ & $15(24)$ & \\
\hline & II & $18(30)$ & $31(52)$ & \\
\hline & III & $1(1)$ & $8(14)$ & \\
\hline \multirow{3}{*}{ Molar occlusion } & I & $41(64)$ & $40(66)$ & \multirow{3}{*}{.757} \\
\hline & II & $19(28)$ & $14(24)$ & \\
\hline & III & $3(3)$ & $6(10)$ & \\
\hline \multirow{4}{*}{ Overjet } & $\leq 1$ & $2(2)$ & $2(3)$ & \multirow{4}{*}{.713} \\
\hline & $>1$ to $\leq 3$ & $45(72)$ & $38(63)$ & \\
\hline & $>3$ to $\leq 6$ & $13(23)$ & $16(27)$ & \\
\hline & $>6$ & $3(3)$ & $4(7)$ & \\
\hline \multirow{4}{*}{ Overbite } & $\leq 0 \%$ & $2(2)$ & $3(5)$ & \multirow{4}{*}{$.05^{*}$} \\
\hline & $>0 \%$ to $\leq 30 \%$ & $48(77)$ & $37(62)$ & \\
\hline & $>30 \%$ to $\leq 50 \%$ & $6(10)$ & $7(12)$ & \\
\hline & $>50 \%$ & $7(11)$ & $13(22)$ & \\
\hline \multirow{2}{*}{ Crowding } & Yes & $15(23)$ & $41(68)$ & \multirow{2}{*}{$<.001^{*}$} \\
\hline & No & $48(77)$ & $19(32)$ & \\
\hline
\end{tabular}

Values are presented as $\mathrm{n}(\%) .{ }^{*}=$ the level of significance was set at $P<.05$. SDB $=$ sleep-disordered breathing.

Despite the fact that dental caries is preventable, it is still the most common childhood chronic disease. According to the United States Centers for Disease Control and Prevention, the percentage of children aged 5 to 19 years with at least one untreated cavity is $18.6 \% .{ }^{35}$ Our analyses suggest that children with higher risk of SDB are at increased risk for dental caries and periodontal disease (ie, inflammation of tissues surrounding the teeth). In fact, caries prevalence in children at high risk of SDB is three times higher than what is reported in the United States general population. This observation is consistent with what other investigators have reported in adults with OSA. ${ }^{19,36,37}$ Inconsistently, Al-Hammad et al. reported lower prevalence of dental caries and periodontal disease among Saudi children with OSA and snoring compared to control. ${ }^{9}$ A possible explanation for the difference between our findings might be the age of the subjects as they only included children 3 to 8 years old. They recruited children with OSA from an ear, nose, and throat clinic and the control subjects from dental clinic. This could explain the higher prevalence of dental caries observed in the control group. Also, they did not take into account demographic or orofacial characteristics, nor did they investigate SDB in their control group.

Although the mechanism is not clear, dental disease and SDB share common risk factors that may increase the likelihood of both conditions. Several studies have shown that people with OSA have an excessive inflammatory response, indicated by increased expression of leukocytes, cytokines, and other inflammatory substances in their upper airway tissues. ${ }^{38}$ The subsequent inflammation can induce swelling and structural changes such as adenotonsillar hypertrophy, thereby narrowing the upper airway passages and leading to upper airway obstruction. Mouth breathing and dry mouth are associated with adenotonsillar hypertrophy, and patients who snore or have OSA have a common clinical finding of dry mouth. Moreover, one of the side effects of the use of a continuous positive airway pressure device (common choice of therapy in treating pediatric OSA) is oral and nasal dryness. ${ }^{16}$ Several studies have demonstrated that people who mouth breathe face increased risk of dental caries, gingivitis, and other oral infection. ${ }^{39}$ Interestingly, adenotonsillar hypertrophy (reflected by Brodsky score of II or more) was a positive predictor for dental caries and gingival bleeding in our study. Additionally, $100 \%$ of the children with SDB in our study were mouth breathers. Therefore, increased inflammatory response and dry mouth could be hypothesized to link SDB, caries, and periodontal diseases. In our study, lack of dental insurance was a strong primary predictor of poor oral health. It is well known that dental insurance is a strong predictor of access to dental care and therefore reduces the prevalence and severity of dental diseases. ${ }^{40,41}$ Thus, increasing the awareness of oral health disparities in the pediatric SDB population is a necessary prerequisite to improving the oral health of this population. 
Figure 1-Dental caries experience of children with and without SDB.



(A) Comparison of the decayed, missing, and filled surfaces index in the primary teeth between SDB+ and the control group (SDB-). (B) Comparison of the decayed, missing, and filled surfaces index in the permanent teeth between SDB+ and the control group (SDB-) $\left({ }^{*}=P<.001\right)$. Boxes indicate the interquartile range, whiskers the maximum and minimum values, and bars inside the boxes median values. $\mathrm{dmfs}=$ decayed, missing, filled surfaces in the primary teeth, DMFS = Decayed, Missing, Filled Surfaces in the permanent teeth, SDB $=$ sleepdisordered breathing.

Figure 2-Periodontal conditions of children with and without SDB.

A

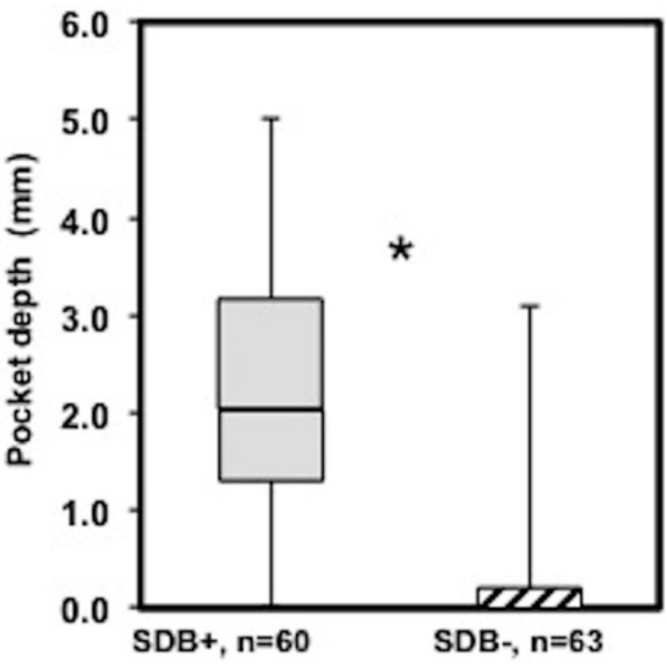

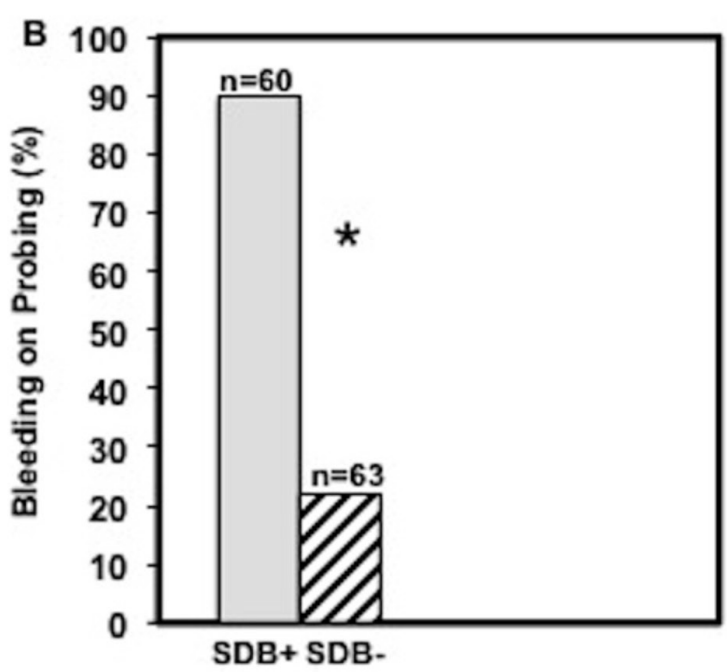

(A) Comparison of the mean probing depth between the two study groups. Boxes indicate the interquartile range, whiskers the maximum and minimum values, and bars inside the boxes median values. (B) Bar charts of the percentage of sites with bleeding on probing in the two study groups. ${ }^{*}=P<.001$. SDB $=$ sleep-disordered breathing. 
There are some limitations in this study. The first limitation is inherent to a cross-sectional design, which does not allow determining causality between the predictors and the outcome. The second is the sample in this study was selected using convenience sampling, which may affect the generalization about the entire population. Additionally, SDB symptoms and the effect of SDB on the children's OHRQoL were both measured using child and caregiver's questionnaires. Thus, the answers to the questionnaires may have been subject to information bias. However, we used validated questionnaires to minimize this bias. Despite the limitations, the current study provides relevant and unprecedented data suggesting higher caries susceptibility, poor periodontal health, and negative effect on OHRQoL among children with SDB.

Clinicians and caregivers should be aware that children with SDB may experience poorer oral health than unaffected peers, and consider tailored preventive regimens for this population. Public health advocates should also take into account the possible effect of SDB on pediatric oral health, implementing policy directed toward improving all aspects of quality of life for these patients.

\section{REFERENCES}

1. Brunetti L, Rana S, Lospalluti ML, et al. Prevalence of obstructive sleep apnea syndrome in a cohort of 1,207 children of southern Italy. Chest. 2001;120(6):1930-1935.

2. Bixler EO, Vgontzas AN, Lin HM, et al. Sleep disordered breathing in children in a general population sample: prevalence and risk factors. Sleep. 2009;32(6):731-736.

3. Horner RL. Pathophysiology of obstructive sleep apnea. J Cardiopulm Rehabil Prev. 2008;28(5):289-298.

4. Lumeng JC, Chervin RD. Epidemiology of pediatric obstructive sleep apnea. Proc Am Thorac Soc. 2008;5(2):242-252.

5. Martikainen S, Pesonen AK, Feldt K, et al. Poor sleep and cardiovascular function in children. Hypertension. 2011;58(1):16-21.

6. Rosen CL, Storfer-Isser A, Taylor HG, Kirchner HL, Emancipator JL, Redline S. Increased behavioral morbidity in school-aged children with sleep-disordered breathing. Pediatrics. 2004;114(6):1640-1648.

7. United States Department of Health and Human Services. Oral Health in America: A Report of the Surgeon General - Executive Summary. Rockville, MD: US Department of Health and Human Services, National Institute of Dental and Craniofacial Research, National Institutes of Health; 2000.

8. Ohyama H, Nakasho K, Yamanegi K, et al. An unusual autopsy case of pyogenic liver abscess caused by periodontal bacteria. Jpn J Infect Dis. 2009;62(5):381-383.

9. Al-Hammad NS, Hakeem LA, Salama FS. Oral health status of children with obstructive sleep apnea and snoring. Pediatr Dent. 2015;37(1):35-39.

10. Schellenberg JB, Maislin G, Schwab RJ. Physical findings and the risk for obstructive sleep apnea. The importance of oropharyngeal structures. Am J Respir Crit Care Med. 2000;162(2 Pt 1):740-748.

11. Banabilh SM, Samsudin AR, Suzina AH, Dinsuhaimi S. Facial profile shape, malocclusion and palatal morphology in Malay obstructive sleep apnea patients. Angle Orthod. 2010;80(1):37-42.

12. Cunha-Cruz J, Scott J, Rothen M, et al. Salivary characteristics and dental caries: evidence from general dental practices. J Am Dent Assoc. 2013;144(5):e31-e40.

13. Leone CW, Oppenheim FG. Physical and chemical aspects of saliva as indicators of risk for dental caries in humans. J Dent Educ. 2001;65(10):1054-1062.

14. Mizutani S, Ekuni D, Tomofuji T, et al. Relationship between xerostomia and gingival condition in young adults. J Periodontal Res. 2015;50(1):74-79.
15. Acar M, Türkcan İ, Özdaş T, Bal C, Cingi C. Obstructive sleep apnoea syndrome does not negatively affect oral and dental health. J Laryngol Otol. 2015;129(1):68-72.

16. Ulander M, Johansson MS, Ewaldh AE, Svanborg E, Broström A. Side effects to continuous positive airway pressure treatment for obstructive sleep apnoea: changes over time and association to adherence. Sleep Breath. 2014;18(4):799-807.

17. Tsuda H, Moritsuchi Y, Higuchi Y, Tsuda T. Oral health under use of continuous positive airway pressure and interest in alternative therapy in patients with obstructive sleep apnoea: a questionnairebased survey. Gerodontology. 2016;33(3):416-420.

18. Sanders AE, Essick GK, Beck JD, et al. Periodontitis and sleep disordered breathing in the Hispanic Community Health Study/Study of Latinos. Sleep. 2015;38(8):1195-1203.

19. Al Habashneh R, Khassawneh B, Khader YS, Abu-Jamous Y, Kowolik MJ. Association between obstructive sleep apnea and periodontitis among male adults attending a primary healthcare facility in Jordan. Oral Health Prev Dent. 2016;14(2):157-164.

20. Petersen PE. The World Oral Health Report 2003: continuous improvement of oral health in the 21st century--the approach of the WHO Global Oral Health Programme. Community Dent Oral Epidemiol. 2003;31 Suppl 1:3-23.

21. Chervin RD, Hedger K, Dillon JE, Pituch KJ. Pediatric sleep questionnaire (PSQ): validity and reliability of scales for sleepdisordered breathing, snoring, sleepiness, and behavioral problems. Sleep Med. 2000;1(1):21-32.

22. Broder HL, McGrath C, Cisneros GJ. Questionnaire development: face validity and item impact testing of the Child Oral Health Impact Profile. Community Dent Oral Epidemiol. 2007;35 Suppl 1:8-19.

23. Mallampati SR, Gatt SP, Gugino LD, et al. A clinical sign to predict difficult tracheal intubation: a prospective study. Can Anaesth Soc J. 1985;32(4):429-434.

24. Brodsky L. Modern assessment of tonsils and adenoids. Pediatr Clin North Am. 1989;36(6):1551-1569.

25. World Health Organization. Oral Health Surveys: Basic Methods. 5th ed. Geneva, Switzerland: World Health Organization; 2013.

26. Gettinger G, Patters MR, Testa MA, et al. The use of six selected teeth in population measures of periodontal status. J Periodontol. 1983;54(3):155-159.

27. Beltrán-Aguilar ED, Eke PI, Thornton-Evans G, Petersen PE. Recording and surveillance systems for periodontal diseases. Periodontol 2000. 2012;60(1):40-53.

28. Arrow P. Child oral health-related quality of life (COHQoL), enamel defects of the first permanent molars and caries experience among children in Western Australia. Community Dent Health. 2013;30(3):183-188.

29. Barbosa Tde S, Tureli MC, Nobre-dos-Santos M, Puppin-Rontani RM, Gavião MB. The relationship between oral conditions, masticatory performance and oral health-related quality of life in children. Arch Oral Biol. 2013;58(9):1070-1077.

30. Krisdapong S, Sheiham A, Tsakos G. Oral health-related quality of life of 12- and 15-year-old Thai children: findings from a national survey. Community Dent Oral Epidemiol. 2009;37(6):509-517.

31. Akgun D, Seymour FK, Qayyum A, Crystal R, Frosh A. Assessment of clinical improvement and quality of life before and after tonsillectomy. J Laryngol Otol. 2009;123(2):199-202.

32. Nikakhlagh S, Rahim F, Boostani H, Shirazi ST, Saki N. The effect of adenotonsillectomy on quality of life in adults and pediatric patients. Indian J Otolaryngol Head Neck Surg. 2012;64(2):181-183.

33. Sfasciotti GL, Marini R, Pacifici A, Ierardo G, Pacifici L, Polimeni A. Childhood overweight-obesity and periodontal diseases: is there a real correlation? Ann Stomatol. 2016;7(3):65-72.

34. Makhija SK, Gilbert GH, Litaker MS, et al. Association between aspects of oral health-related quality of life and body mass index in community-dwelling older adults. J Am Geriatr Soc. 2007;55(11):1808-1816.

35. National Center for Health Statistics (US). Health, United States, 2016: With Chartbook on Long-term Trends in Health. Hyattsville, MD: National Center for Health Statistics (US); 2017. 
36. Seo WH, Cho ER, Thomas RJ, et al. The association between periodontitis and obstructive sleep apnea: a preliminary study. J Periodontal Res. 2013;48(4):500-506.

37. Gamsiz-Isik H, Kiyan E, Bingol Z, Baser U, Ademoglu E, Yalcin F. Does obstructive sleep apnea increase the risk for periodontal disease? A case-control study. J Periodontol. 2017;88(5):443-449.

38. Unnikrishnan D, Jun J, Polotsky V. Inflammation in sleep apnea: an update. Rev Endocr Metab Disord. 2015;16(1):25-34.

39. Brosky ME. The role of saliva in oral health: strategies for prevention and management of xerostomia. J Support Oncol. 2007;5(5):215-225.

40. Malecki K, Wisk LE, Walsh M, McWilliams C, Eggers S, Olson M. Oral health equity and unmet dental care needs in a population-based sample: findings from the Survey of the Health of Wisconsin. Am J Public Health. 2015;105 Suppl 3:S466-S474.

41. Thompson B, Cooney P, Lawrence H, Ravaghi V, Quiñonez C. The potential oral health impact of cost barriers to dental care: findings from a Canadian population-based study. BMC Oral Health. 2014;14:78.

\section{ACKNOWLEDGMENTS}

The authors are grateful to Drs. Michael L. Cunningham, Sue Herring, Kelly Evans and Hitesh Kapadia for valuable support and advice throughout this study. The authors also thank William Tressel for his guidance in statistical analysis. Many thanks to all the study participants who made this study possible.

\section{SUBMISSION \& CORRESPONDENCE INFORMATION}

Submitted for publication April 28, 2017

Submitted in final revised form December 5, 2017

Accepted for publication December 18, 2017

Address correspondence to: Maida Chen, MD, Seattle Children's

Hospital, 4800 Sand Point Way, NE MS\#OC.7.720, Seattle, WA 98105;

Tel: (206) 987-4237; Email: Maida.chen@seattlechildrens.org

\section{DISCLOSURE STATEMENT}

This was not an industry-supported study. The authors declare no potential conflicts of interest with respect to the authorship and/or publication of this article. All work related to this study was performed at the Department of Pediatric Dentistry, School of Dentistry, University of Washington, Seattle, WA, USA. 